\title{
O CONTROLE JUDICIAL DAS POLÍTICAS PÚBLICAS E A IMPLEMENTAÇÃO DOS DIREITOS FUNDAMENTAIS SOCIAIS. O ENTENDIMENTO DOS TRIBUNAIS SUPERIORES
}

\section{THE JUDICIAL CONTROL OF PUBLICS POLICIES AND THE IMPLEMENTATIONS OF FUNDAMENTAL SOCIAL RIGHTS. THE UNDERSTANDING OF SUPERIOR COURTS}

Camila de Bortoli Rossatto ${ }^{1}$

Aline Sueli de Salles Santos ${ }^{2}$

\begin{abstract}
RESUMO
Visando garantir a efetivação dos direitos fundamentais sociais, existe a possibilidade do controle judicial das políticas públicas pelo Poder Judiciário. Neste sentido, com o objetivo de realizar uma análise teórica da legitimidade desta intervenção, foram selecionadas cinco decisões que refletem o posicionamento preponderante dos Tribunais. Dessas, quatro decisões foram proferidas pelo Supremo Tribunal Federal (STF) e uma pelo Superior Tribunal de Justiça (STJ), todas versando sobre a questão da legitimidade constitucional do controle e intervenção do Poder Judiciário na implementação das políticas públicas. A importância deste artigo se justifica ante a existência de algumas questões controversas nestes julgamentos. Entre elas, cita-se a intangibilidade dos direitos fundamentais (e princípio do mínimo existencial) frente à cláusula da reserva do possível, bem como a legitimidade da ingerência do Poder Judiciário nos demais poderes. Por fim, nota-se uma possível afronta ao princípio constitucional da separação dos poderes. Assim, observando as decisões dos Tribunais Superiores, bem como o entendimento da moderna doutrina a respeito do assunto ora proposto, realizou-se uma pesquisa teórica documental. Através de nossa análise, pôde-se concluir que o princípio fundamental da dignidade da pessoa humana justifica o controle judicial das políticas públicas pelo Poder Judiciário.
\end{abstract}

PALAVRAS-CHAVE: Controle judicial das políticas públicas. Dignidade humana. Direitos fundamentais sociais. Mínimo existencial. Separação dos poderes.

\footnotetext{
ABSTRACT

${ }^{1}$ Especialista em Direito Administrativo pela Universidade Federal do Tocantins (UFT). Advogada. Email: camila.rossatto@hotmail.com

2 Doutora em Direito pela Universidade de Brasília $(U n B)$ e professora de Direito na Fundação Universidade Federal do Tocantins (UFT), onde ministra aulas de graduação e pós-graduação (lato e stricto sensu), e desenvolve atividades de pesquisa e extensão. Possui graduação em Direito pela Universidade de São Paulo (USP), mestrado em Direito pela Universidade do Vale do Rio dos Sinos (UNISINOS ) e especialização em Direito Administrativo pelo Instituto Brasiliense de Direito Público (IDP - 2013), onde é colaboradora (desde 2010). Tem experiência na modalidade de educação à distância e na administração de cursos superiores. Atua com ênfase em Direito Administrativo, Direitos Humanos, Ensino Jurídico, Judicialização da política e Justiça de Transição. Foi Conselheira da Comissão de Anistia do Ministério da Justiça (2008-2016). E-mail: alinesalles@uft.edu.br
} 
To ensure the implementation of fundamental social rights the Judiciary Power may interpose control over public policies. In this sense, in order to make a theoretical analysis of the legitimacy of such interventions, we selected five preponderant Court positions. The Federal Supreme Court issued four of these and the another by the Superior Justice Court. All them dealt with constitutional legitimacy of control and intervention of Judiciary Power over public policies implementation. The importance of this paper is justified by the existence of controversial issues in these judgments. The intangibility of fundamental rights (and the existential minimum principle) faces the clause of reserve for contingencies, as well as the legitimacy of Judiciary Power interference over other powers. At last, there is a possible affront to the principle of constitutional separation of powers. Therefore, observing the decisions from Superior Courts, as well as the understanding of modern doctrine regarding issues here proposed we performed a theoretical documental research. Based on our analysis we concluded that the fundamental dignity of human being justifies the judicial control of public policies by Judiciary Power.

KEY WORDS: Judicial control of public policies. Human dignity. Fundamental social rights. Existential minimum. Separation of powers.

\section{CONSIDERAÇÕES INICIAIS}

A presente pesquisa possui como objetivo apresentar o entendimento dos Tribunais Superiores a respeito do controle judicial das políticas públicas implementadoras dos direitos fundamentais sociais, bem como os desdobramentos doutrinários a respeito do tema. Para isso, foram escolhidas decisões que demonstram o posicionamento majoritário dos referidos Tribunais no que tange à legitimidade do Poder Judiciário no controle das políticas públicas, observando-se fatores relevantes como a intangibilidade dos direitos fundamentais e o óbice financeiro justificado pela cláusula da reserva do possível, bem como suposta ingerência indevida do Poder Judiciário nos demais poderes, ferindo o princípio da separação dos poderes.

A primeira decisão analisada é a Arguição de Descumprimento de Preceito Fundamental (ADPF) de número 45, julgada pelo Ministro Celso de Mello. Trata-se de ação contra veto presidencial que incidiu sobre o parágrafo $2^{\circ}$ do artigo 55 da Lei 10.707 de 30 de julho de 2003. O dispositivo vetado preceituava que se consideram ações e serviços públicos de saúde, a totalidade das dotações do Ministério da Saúde, deduzidos os encargos previdenciários da União, os serviços da dívida e as parcelas das despesas do Ministério, financiadas com os recursos do Fundo de 
Combate de erradicação da Pobreza. O autor da ação arguiu que houve, no veto presidencial, desrespeito ao preceito fundamental decorrente da Emenda Constitucional de número 29, de 13 de setembro de 2000, que garante os recursos mínimos a serem aplicados nas ações referentes à saúde. Contudo, o presidente, logo após o veto ser questionado na ADPF, remeteu ao Congresso Nacional o projeto de lei que transformado na Lei 10.707 de 30 de julho de 2003, restaurou, na sua integralidade 0 art. 59 parágrafo $2^{\circ}$ da referida lei, dele fazendo constar a mesma norma e por este motivo, supriu a omissão motivadora do ajuizamento da ação. Posteriormente, ainda no julgamento da ação, o Ministro abordou questões como a legitimidade constitucional do controle e da intervenção do Poder Judiciário em tema de implementação de políticas públicas quando configurada hipótese de abuso governamental. Por fim, observou aspectos referentes à cláusula da reserva do possível e a intangibilidade do núcleo consubstanciador do mínimo existencial.

A segunda decisão consiste no julgamento do Agravo Regimental interposto pela União contra o indeferimento da Suspensão da Tutela Antecipada (STA) 175, proferida pelo Ministro do STF Gilmar Mendes, que versa sobre o fornecimento de medicamento de alto custo para tratamento de doença neurodegenerativa rara. Os aspectos controversos de tal decisão residem nos argumentos de que a concessão à tutela viola o princípio da separação dos poderes, os regulamentos do Sistema Único de Saúde (SUS), desconsiderando a função exclusiva da Administração Pública em definir a execução das políticas públicas, gerando assim, indevida interferência do Judiciário nas diretrizes das políticas públicas de saúde. Contudo, o objeto da análise de tal decisão serão os interessantes parâmetros fixados pelo Ministro Gilmar Mendes no que diz respeito à judicialização das políticas públicas relacionadas à saúde e por analogia, aos outros direitos sociais.

As demais decisões, quais sejam, o Recurso Extraordinário (RE) 639.337/SP, Recurso Especial (REsp) 1.041.197/MS e o Recurso Extraordinário (RE) 482.611/SC, tratam sobre questões similares referentes à legitimidade constitucional da intervenção do Poder Judiciário em casos excepcionais de omissão ou abuso do poder público na implementação das políticas públicas previstas na Constituição e garantidoras dos direitos sociais. Nos casos em questão, os preceitos fundamentais violados se referem à saúde, escola e proteção integral a juventude. Não obstante, observaram-se ainda nos julgamentos mencionados, questões referentes à dignidade da pessoa humana e a intangibilidade do princípio do mínimo 
existencial, bem como suposta violação a separação dos poderes e a cláusula da reserva do possível.

Desse modo, quatro são os aspectos fundamentais desses julgamentos. A legitimidade do controle judicial das políticas públicas, a possível violação do princípio da separação dos poderes, a dignidade da pessoa humana e o mínimo existencial e por fim, o óbice orçamentário protegido pela cláusula da reserva do possível.

Quando o poder público falha na implementação das políticas públicas asseguradoras de direitos fundamentais, o Poder Judiciário é invocado para sanar o vício e acaba controlando o modo de execução dessas políticas. Nesse sentido, se suscita a ingerência indevida do judiciário nos demais poderes e nos critérios de oportunidade e conveniência da Administração Pública.

Entretanto, se tratando de direitos fundamentais de aplicabilidade imediata, porquanto, essenciais para uma vivência digna, podem estar sujeitos aos critérios de oportunidade da Administração?

É o que se pretende responder no decorrer deste trabalho, através da análise das decisões jurisprudenciais já mencionadas e da doutrina contemporânea.

\section{CONTROLE JUDICIAL DAS POLÍTICAS PÚBLICAS}

A função do Estado, com o decorrer dos anos, muito se modificou no sentido de promover a efetivação de uma ordem social mais justa. O contexto jurídico social atual exige uma prestação ainda mais positiva do administrador a fim de prover, ao menos minimamente, os meios necessários para uma vivência digna, principalmente após a elucidação dos direitos fundamentais sociais na Constituição Federal de 1988. Tais ações prestacionais são realizadas pelo Estado a partir da elaboração de políticas públicas.

Partindo desse pressuposto, de uma maneira sucinta, políticas públicas significam um conjunto de ações, tarefas e intervenções estatais que visam alcançar a efetivação de objetivos politicamente escolhidos como prioritários. São atos da Administração voltados principalmente para ações prestacionais de cunho social, ou seja, um grupo de metas coletivas ordenadas no sentido de alcançar objetivos já definidos.

Ademais, em regra, é principalmente por intermédio das políticas públicas 
que se dá a execução dos direitos fundamentais sociais, "uma vez que pouco vale o mero reconhecimento formal de direitos se ele não vem acompanhado de instrumentos para efetivá-los" (FREIRE JR apud FONTE, 2009, p. 07). Assim, as políticas públicas, se tratando dos direitos sociais, são o meio hábil para executá-los.

\begin{abstract}
Política pública é o programa de ação governamental que resulta de um processo ou conjunto de processos juridicamente regulados - processo eleitoral, processo de planejamento, processo de governo, processo orçamentário, processo legislativo, processo administrativo, processo judicial - visando coordenar os meios à disposição do Estado e as atividades privadas, para a realização de objetivos socialmente relevantes e politicamente determinados. Como tipo ideal, a política pública deve visar à realização de objetivos definidos, expressando a seleção de prioridades, a reserva de meios necessários à sua consecução e o intervalo de tempo em que se espera o atingimento dos resultados. (BUCCI, 1997, p. 81)
\end{abstract}

Em consonância com o pensamento supramencionado, de fato é necessário que haja essa organização de estabelecimento de prioridades, alocação dos recursos disponíveis e o respectivo tempo de aplicação para garantir a perfeita execução, sob pena de ferir, principalmente, a Constituição Federal no que tange aos direitos sociais, seja pela não realização e implementação das políticas necessárias, seja pela ilegalidade ou pelo desvio de finalidade nos atos administrativos, autorizando assim, a interferência do Poder Judiciário.

Se tratando de direitos fundamentais prestacionais, quando existe um direito subjetivo, conforme corrobora Freire Jr. (2004), não se pode aceitar a minimização da constituição a mera letra de lei, sem efetividade. E é dessa afirmação que se reconhece a extrema importância que as políticas públicas possuem no constitucionalismo moderno, atuando como meio de reconhecimento desses direitos e normatização das relações sociais.

O fundamento mediato das políticas públicas, o que justifica o seu aparecimento, é a própria existência dos direitos sociais - aqueles, dentre o rol de direitos fundamentais do homem, que se concretizam por meio de prestações positivas do Estado. Enquanto os direitos individuais, ditos direitos fundamentais de primeira geração, consistem em liberdades, os direitos sociais, ditos de segunda geração, consistem em poderes, que só podem ser realizados se for imposto a outros (incluídos aqui os órgãos públicos) um certo número de obrigações positivas. A função estatal de coordenar as ações públicas (serviços públicos) e privadas para a realização de direitos dos cidadãos - à saúde, à habitação, à previdência, à educação - legitima-se pelo convencimento da sociedade quanto à necessidade de realização desses direitos sociais (BUCCl, 1997, p. 90). 
As políticas públicas podem ser entendidas como instrumentos de ação dos governos, o que explicaria a maior importância para a elaboração e fixação de metas a serem cumpridas em determinado lapso temporal. Assim, conforme pontua Bucci (1997), o fundamento imediato das políticas públicas seria a função de governar, enquanto o fundamento mediato seria a própria existência dos direitos sociais.

A controvérsia ocorre nos casos em que a exigência desses direitos constitucionais ocorre judicialmente, diante da falha na atuação positiva do Executivo, quando o Judiciário determina a forma como tais políticas, a princípio de caráter discricionário, serão executadas. Pode o Poder Judiciário interferir no modo de execução das políticas públicas de competência do Poder Executivo?

Primeiramente, basta analisar a atual conjuntura jurídica para perceber que a judicialização das políticas públicas é amplamente utilizada, sendo o entendimento majoritário dos Tribunais Superiores. Conforme ensina Barroso (2009), é indubitável que a teoria da legitimidade do controle constitucional foi amplamente vitoriosa. Assim, a judicialização das políticas públicas seria legítima apenas para casos excepcionais, quando o Estado não executa o disposto na Constituição no que tange a prestação dos direitos necessários para atender, ao menos minimamente, o princípio da dignidade da pessoa humana.

Ademais, se as políticas públicas são meios eficazes para implementação dos direitos prestacionais sociais e não pode o Poder Judiciário, segundo preceitua a Constituição, imiscuir-se de apreciar lesão ou ameaça a direito, parece restar clara, conforme argumentou Ferreira (2013), a possibilidade de controle das políticas públicas pelo Judiciário.

Entretanto, apesar dos avanços jurisprudenciais e doutrinários favoráveis acerca do controle judicial de políticas públicas, note-se que conforme observado anteriormente é grande a celeuma que reside na limitação à atuação do Judiciário. Como exemplo, ao julgar a STA 175, o STF pontuou que a problemática dos direitos sociais se encontra atualmente em uma posição desconfortável. Segundo este, paira sobre a teoria dos direitos sociais uma carga de indeterminação, ambiguidade e vagueza.

A questão ganha complexidade diante de questionamentos como 0 desrespeito ao princípio constitucional da separação dos poderes e a questão democrática, ou então, que o Poder judiciário não teria legitimidade para apreciar questões políticas vinculadas à efetivação dos direitos fundamentais sociais. 
Ademais, argumenta-se que haveria a violação do critério discricionário da Administração e por fim, a questão orçamentária e a cláusula da reserva do possível.

\section{1 Controle Judicial das Políticas Públicas e a Revisão Judicial dos Atos Administrativos Discricionários}

Não obstante as subjeções relativas ao princípio da separação dos poderes e a legitimidade do Judiciário, óbice bastante importante, contrastando com a intangibilidade e a obrigatória execução dos direitos socais, é a questão da discricionariedade.

Em regra, decisões sobre a execução das políticas públicas pelo Poder Executivo são atos administrativos discricionários, pois se organizam baseadas em interesses não somente de ordem social, mas políticos, tendo o Estado uma margem legal de atuação nesse sentido, podendo executá-las, ou não, conforme os critérios mais oportunos e convenientes e de acordo com os recursos disponíveis para tal.

Atos discricionários são aqueles que a Administração pode praticar com uma margem de liberdade, limitada pela lei, decidindo quanto à conveniência, modo de efetivação, conteúdo e oportunidade. Ademais, segundo discorrem Alexandrino e Paulo (2012), além da discricionariedade conhecida quando a lei explicitamente confere, a doutrina contemporânea reconhece ainda a existência do critério discricionário quando a lei empregar conceitos indeterminados ou subjetivos.

\footnotetext{
A discricionariedade decorre da hipótese da norma, quando os pressupostos de fato por ela enunciados - como autorizadores ou exigentes de um comportamento - são descritos mediante conceitos [...] práticos. Isto é, se os antecedentes fáticos que determinam a prática de um ato [...], estão delineados por meio de palavras vagas, imprecisas, cabe à administração determinar-lhes concretamente 0 alcance na espécie, cingida a certos limites. (MELLO, 2008, p. 958)
}

Assim, a Administração decidirá se o fato ocorrido está ou não incluso no conceito determinado, aplicando, ou não, o ato administrativo subsequente.

Havendo margem de discrição no motivo ou no objeto do ato 
administrativo, existe juízo de mérito. E "o Poder Judiciário não pode substituir a Administração nesse juízo de valor, porque se trata de um juízo de mérito administrativo" (PAULO; ALEXANDRINO, 2012, p. 126). Essa é a regra.

\begin{abstract}
Mérito do ato é o campo de liberdade suposto na lei e que efetivamente venha a remanescer no caso concreto, para que o administrador, segundo critérios de oportunidade e conveniência, decida-se entre duas ou mais soluções admissíveis perante a situação vertente, tendo em vista o exato entendimento da finalidade legal, ante a impossibilidade de ser objetivamente identificada qual delas seria a única adequada. (MELLO, 2008, p. 955).
\end{abstract}

Não obstante, os atos discricionários "estão sujeitos a amplo controle de legalidade perante o Judiciário. Ao juiz é proibido somente revisar o mérito do ato discricionário" (MAZZA, 2013, p. 235). Logo, em regra é possível o controle judicial da discricionariedade administrativa, desde que respeitados os limites assegurados pela lei à atuação da Administração.

Entretanto, maior parte da doutrina contemporânea, analisando a crescente reclamação por uma atuação mais positiva do Estado, tem observado a problemática referente à discricionariedade administrativa e o controle judicial, entendendo que afirmação de que o mérito do ato administrativo discricionário não pode ser objeto de análise judicial deve ser entendida de maneira relativizada.

Nesse diapasão, leciona Justen Filho (2011) que a escolha realizada pelo administrador, em regra, não deve ser suscetível ao controle judicial. Contudo, observando-se que a discricionariedade é considerada autonomia limitada do administrador, existem defeitos de mérito passíveis de revisão, quando, por exemplo, a decisão for arbitrária, desarrazoada ou inapta a surtir a finalidade desejada.

É incontestável que o poder público necessite da autonomia e da margem de liberdade conferida pela legislação a título de discricionariedade, mas essa prerrogativa não confirma a hipótese de que mesmo se tal ato for inapto ao fim que se destina, não pode o judiciário interferir, posto que se trate do mérito do ato e do juízo de oportunidade e conveniência da Administração. Nesse sentido:

A esfera de liberdade administrativa pode resultar da hipótese da norma jurídica a ser implementada, do mandamento dela ou até mesmo de sua finalidade. Ponha-se reparo e sublinhadamente que em qualquer das hipóteses aventadas (exemplificando a atuação discricionária da administração em relação à saúde, educação, entre outros), tal liberdade é 
sempre relativa, sempre limitada e sempre contrastável pelo judiciário, que deverá confiná-la em seus adequados redutos. (MELLO, 2008, p. 958).

Portanto, quando o ato administrativo dotado de discrição ensejar hipóteses de desvio de finalidade, inadequação, arbítrio, falta de razoabilidade e até mesmo a falta desse ato através da omissão, deve ser passível de revisão judicial para a posterior adequação ao caso concreto.

Não obstante, o STF entende que o Poder Executivo não pode utilizar da prerrogativa da discricionariedade, haja vista a intangibilidade, urgência e extrema importância da aplicação e efetivação desses direitos constitucionais. Dessa forma, ao julgar o RE 639.337/SP, entendeu que a educação infantil, por ser direito fundamental, não pode se submeter à avaliação meramente discricionária, não se subordinando a questões de programatismos governamentais.

Dessa forma, interfere o Poder Judiciário nos critérios de oportunidade e conveniência conferidos a Administração Pública a fim de sanar, não mais apenas a ilegalidade, mas os defeitos no mérito do ato administrativo suscetíveis de revisão.

Entretanto, não se pode deixar de conferir a devida importância no que tange a divergência existente no controle judicial dos atos discricionários da Administração, principalmente referente aos direitos sociais. Conforme se verificou, enquanto a Administração avoca que os critérios discricionários e a sua margem de autonomia e liberdade não podem ser objeto de revisão judicial, o Judiciário argui que se existirem no ato inconformidades, não somente quanto à ilegalidade, mas no juízo de valor, essa hipótese é perfeitamente admissível.

Argumentar a legitimidade da interferência do Judiciário na atuação da Administração pública é tarefa complexa. Mello (2008) apontou inteligente alternativa para o impasse em questão. Primeiramente, discorre que se a lei, nos casos discricionários, confere medidas diferentes, certamente pretende que cada questão seja analisada sob o enfoque individual, conforme a natureza de cada caso. Ou seja, que sejam tomadas soluções diversas para casos diversos, decidindo de maneira adequada cada situação.

E continua o raciocínio no sentido de que a discricionariedade é necessária ao nível da norma, mas não significa que terá a mesma força diante do caso concreto e nem que existirá em qualquer situação que ocorra. Ou seja, a discricionariedade é uma possibilidade reservada pela lei à Administração, mas não é absoluta, certa que estará presente em qualquer caso abrangido pela lei. 
Observados estes dois apontamentos, entendeu que para que o ato seja adequado, não basta que o administrador apenas alegue que utilizou o critério discricionário. É necessário mais. Assim, pode o juiz verificar, adotando o critério da razoabilidade, se o ato administrativo foi compatível com a finalidade da norma a ser aplicada, e caso julgue ser a providência adotada incabível, poderá adequá-la a realidade jurídica social.

Por fim, concluiu arguindo que a discrição ocorre nos casos em que seja impossível distinguir com precisão incontroversa qual a solução mais adequada e idônea para o caso em questão. Contudo, se o posicionamento adotado for seguramente inadequado, poderá ser revisado pelo judiciário, desde que o juízo seja equilibrado e razoável, reconhecendo a inexistência da discricionariedade naquele ato que foi suscetível de avaliação.

Tendo em vista o império da lei, que delimita a questão da discricionariedade, o Poder Judiciário não mais se limita a analisar apenas os aspectos legais, podendo avaliar ainda, o juízo de oportunidade e conveniência, desde que não observados os critérios de moralidade e razoabilidade. Em outras palavras, o ato administrativo, mesmo que revestido de legalidade, poderá ser anulado pelo errôneo juízo de valor realizado pela Administração, que não agiu de modo que o ato atinja o fim ao qual se destinou, desobedecendo à previsão legal.

Exemplificando, se a Constituição considera como direitos fundamentais sociais os elencados no seu artigo 6ำ e a Administração, calcada no juízo de valor baseado na oportunidade e conveniência não atende tal requisito, certamente estaria indo contra a razoabilidade, seja pela intangibilidade dos direitos fundamentais, seja pelo desrespeito a Constituição. Dessa forma, mesmo sendo regra que os atos administrativos discricionários não podem ser objeto de análise judicial quanto ao mérito, em respeito à separação dos poderes, se a decisão não estiver pautada nos critérios da razoabilidade, o Poder Judiciário deve interferir na execução do ato administrativo viciado.

Não obstante, o próprio conceito de ato discricionário vem sendo entendido de maneira diferenciada da máxima de que a discricionariedade é o espaço de decisão do administrador, decorrente da diferenciação de atos administrativos discricionários e vinculados.

As transformações recentes sofridas pelo direito administrativo tornam imperiosa a revisão da noção de discricionariedade administrativa. Com 
efeito, pretende-se caracterizar a discricionariedade, essencialmente, como um espaço carecedor de legitimação. Isto é, um campo não de escolhas puramente subjetivas, mas de fundamentação dos atos e políticas públicas adotadas, dentro dos parâmetros jurídicos estabelecidos pela Constituição e pela lei. (BINENBOJM, 2008, p. 16).

Assim, a mencionada revisão do conceito de discricionariedade se justifica porque, durante anos não houve uma obediência aos princípios constitucionais e um maior controle material da motivação dos atos administrativos relacionados à execução de políticas públicas.

Em resumo, embora o Judiciário interfira nas questões de oportunidade e conveniência da Administração, a posição de que não há legitimidade nessa intervenção caiu por terra à medida que o judiciário, agindo com ponderação, de modo razoável e proporcional, primando pela soberania da Constituição e a vedação do retrocesso social, assegura a dignidade da pessoa humana e o mínimo existencial controlando o modo de implementação das políticas públicas até então negadas pelo Estado, seja por ato comissivo desarrazoado que se desvia da sua finalidade, seja por omissão. Embora existam muitos argumentos contundentes por parte do Estado no sentido de não implementar as políticas públicas reclamadas, a dignidade da pessoa humana é preceito norteador da Constituição e os direitos fundamentais, por se tratarem de um núcleo material de condições mínimas a uma vivência decente, são intangíveis e indisponíveis.

\subsection{A legitimidade do Poder Judiciário no Controle Judicial das Políticas Públicas}

O Poder Judiciário não possui competência para efetivar as questões de políticas públicas e nem o magistrado a prerrogativa de impor sua vontade sobre várias hipóteses as quais a maioria escolheu uma em específico. Logicamente, admitindo-se que o Poder Judiciário assumisse essa função, estaria havendo concentração de poderes, violando de plano a separação funcional das funções Estatais. Este posicionamento é incontroverso.

Entretanto, nos diversos casos em que o disposto como fundamental na Constituição Federal é desrespeitado injustificadamente pelo administrador, fugindo da finalidade a qual estava vinculada, o Judiciário é invocado a fim de interferir e restabelecer a ordem jurídica violada, não podendo imiscuir-se da atuação 
jurisdicional, pois não pode ser afastada da apreciação do Judiciário, lesão ou ameaça ao direito, como ocorre no caso em questão.

Assim, já que o Judiciário deve atuar sempre que provocado, a questão controversa reside, primeiramente, na amplitude da legitimidade do Judiciário quando se torna necessária a intervenção no modo de aplicação das políticas públicas.

A resposta consiste em um argumento bastante plausível, baseado na ponderação e na racionalidade na atividade jurisdicional. Explica Barcellos (2011), que o primeiro aspecto a ser considerado é o da dignidade da pessoa humana. Por ser basilar e norteador da Constituição. Por conseguinte, tanto o princípio da separação dos poderes e o princípio majoritário (vontade democrática das maiorias) devem atuar harmonicamente com a positivação da dignidade e do mínimo existencial, reconhecendo a legitimidade do Judiciário para determinar as políticas adequadas à efetivação de tais direitos. A ideia é que para a satisfação da dignidade humana, os princípios acima elucidados sejam flexibilizados, cedendo um pouco do seu espaço e operando juntos e satisfatoriamente. Assim, o limite de atuação do Judiciário estaria pautado em um patamar mínimo de condições materiais (avaliando o mínimo existencial ou a fundamentabilidade dos direitos sociais ou a indisputabilidade da dignidade), que abaixo deste, se estaria violando o princípio da dignidade da pessoa humana.

Desse modo, o fator principal autorizativo da legitimação da interferência do Judiciário na Administração é o desrespeito à dignidade humana, que é princípio fundamental do ordenamento jurídico vigente.

Dito isto, os Tribunais elencam ainda, uma série de outras hipóteses que legitimam essa interferência, sempre calcadas na fundamentabilidade dos preceitos Constitucionais. Nesse sentido, a omissão do Estado que deixa de cumprir preceito constitucional é qualificada, de acordo com o entendimento do STF no julgamento da ADPF 45, como comportamento de extrema gravidade político jurídica, vez que mediante inércia, ofende os direitos que se fundam na Constituição, impedindo a aplicabilidade dos seus postulados e princípios. Assim, em hipóteses excepcionais, quando a Administração age sem motivação; de maneira desarrazoada ou com omissão; extrapola os limites da sua competência; se desvia da finalidade a qual está vinculada; compromete a eficácia e efetividade dos direitos individuais e coletivos através de ato inapto, também está autorizado o Judiciário a intervir e 
corrigir tais distorções.

Ao analisar o mérito do agravo interposto ao indeferimento da STA 175, relacionada ao fornecimento de medicamentos de alto custo para tratamento de doença grave, o STF apontou interessantes parâmetros no que diz respeito à judicialização das políticas públicas relacionadas à saúde.

Primeiramente, observou que o problema não reside necessariamente na judicialização das políticas públicas em matéria de saúde, isso porque na maioria dos casos, o que de fato ocorre é apenas a determinação judicial do efetivo cumprimento das políticas públicas já existentes. Assim, o primeiro parâmetro é analisar se existe ou não política estatal referente à prestação de saúde prestada pela parte. Se não houver, é imprescindível observar se a não prestação decorre de uma omissão administrativa, de uma decisão de não fornecê-la ou se de uma vedação legal a sua dispensação. O segundo parâmetro consiste em analisar se existe motivação para o não fornecimento da prestação de saúde pleiteada.

Logicamente, tal raciocínio pode ser utilizado através de uma interpretação analógica para os demais direitos sociais. Assim, se existir uma política determinadora de um direito prestacional, pode o judiciário intervir a fim de determinar sua execução e não havendo, interessante observar se existem causas motivadoras ou que justifiquem a omissão ou a negativa a prestação do direito pleiteado, e caso não existam, deve intervir a fim de garantir a referida prestação.

Nesse sentido, o STJ, no julgamento do REsp. 1041.197/MS entendeu que é possível a atuação do Poder Judiciário no controle das políticas públicas, desde que não seja de forma indiscriminada, atuando sempre que a Administração Pública viole a efetivação dos direitos fundamentais, através da falta injustificada de execução de programas de governo.

Além da indubitável proteção dos direitos sociais básicos, existem dois fatores importantes que levam o Judiciário a um comportamento afirmativo em relação à Administração pública. No RE 639.337/SP, observou-se primeiramente, que deve prevalecer a primazia da Constituição Federal, não podendo ser reduzida a mera letra de lei e que em muitos casos, por conveniência e oportunidade na omissão dos poderes públicos é transgredida. Na verdade, o posicionamento é de que quando o Supremo supre tais omissões inconstitucionais e toma medidas para restaurar a Constituição violada, cumpre sua missão institucional e demonstra respeito à Lei Maior. 
Em segundo lugar, decorrente do desrespeito à primazia da Constituição, há uma preocupação grande com o fenômeno da erosão da Consciência Constitucional, motivado pela desvalorização funcional da Constituição, através da abstenção do Poder Público de cumprir, ainda que parcialmente, preceito Constitucional.

Segundo o STF, quando o poder público se abstém de cumprir, ainda que parcialmente, o dever de implementar as políticas públicas, ofende a integridade da Constituição Federal, estimulando o fenômeno da erosão constitucional. Quando o Poder Judiciário interfere execução de tais políticas públicas, neutraliza os efeitos nocivos provocados pela omissão do Estado, que se traduzem em inaceitável insulto aos direitos básicos assegurados pelo texto constitucional.

Outro argumento que legitima o controle Judicial das políticas públicas é o de que a lei não pode prever as reais necessidades do direito material em si, pois assumem contornos diversos dependendo do caso em questão. O problema reside, "em como juridicizar o Estado social, como estabelecer e inaugurar novas técnicas ou institutos processuais para garantir os direitos sociais básicos, a fim de fazê-los efetivos" (BONAVIDES, 2003, p. 373). Diante dessa realidade, naturalmente o Judiciário adequou os instrumentos processuais de modo a sanar a tutela dos direitos fundamentais pretendidos, até então, negados pelo Estado.

\section{A QUESTÃO ORÇAMENTÁRIA: CLÁUSULA DA RESERVA DO POSSÍVEL}

A ideia de reserva do possível surgiu nos Tribunais da Alemanha, ao julgar um caso referente ao direito de acesso ao ensino superior. Dessa forma, "se sustentou que os direitos sociais estavam submetidos à reserva do possível, no sentido daquilo que o individuo de maneira razoável pode pretender da sociedade" (PULIDO apud SARLET, 1998. p. 260). Assim, restou firmada jurisprudência Alemã no sentido de que a prestação reclamada, consoante explica Sarlet (1998), deve ser correspondente ao que a pessoa pode exigir razoavelmente da sociedade.

Todavia, a reserva do possível se tornou objeto de maiores estudos nos anos noventa, depois da edição da obra de Stefhen Holmes e Cass R. Sustein "The cost of rigths", pois segundo Barcellos (2011), os autores realizaram uma análise econômica do custo dos direitos sociais e individuais, incitando duas visões a respeito do assunto. A primeira, no tocante ao direito em si, que não pode ser 
estudado de forma isolada. Ou seja, para a efetivação dos direitos sociais é necessário que se observe o contexto em que estão inseridos, de modo que mesmo a melhor administração não poderá fazer surgirem recursos onde eles não existam.

Por conseguinte, verificou-se que não somente os direitos sociais possuem custos para o Estado e este é um aspecto importante, uma vez que os demais direitos (individuais e políticos), para serem assegurados, também exigem dinheiro, demandando gastos por parte da Administração Pública. Nesse contexto, "a diferença entre os direitos sociais e individuais, no que toca ao custo, é uma questão de grau, e não de natureza" (BARCELLOS, 2011. P. 280). Em outras palavras, é plausível a afirmação de que os direitos sociais exijam a viabilização de maiores recursos financeiros do que os direitos individuais, mas isso não significa que estes não possuam custos.

Logo, as respectivas teorias de que a questão da efetivação dos direitos não pode ser abordada de forma isolada, devendo ser contextualizada com as condições socioeconômicas e de que tais direitos demandam aplicações financeiras, é a ideia fundamental para a discussão sobre a reserva do possível.

Dessa forma, partindo-se da percepção de que a concretização dos direitos fundamentais sociais é um dos fatores que asseguram a vivência digna da pessoa humana e, por conseguinte, o cumprimento de um núcleo mínimo de condições existenciais (mínimo existencial), considerando-se ainda, que a efetiva implementação dos referidos direitos é onerosa, pois depende da conjuntura econômica Estatal, vislumbra-se, notadamente, a problemática pertinente ao assunto em questão.

Ora, uma vez que existem prestações sociais carentes de efetivação, existe um verdadeiro problema consistente na relevância econômica que possui essa concretização dos direitos a prestações em oposição às reservas financeiras do Estado, de modo que as necessidades de caráter social prestacional são inúmeras, contrastando diretamente com as reservas orçamentárias, que por sua vez, são limitadas.

Sustenta Sarlet (1998), que diretamente vinculada à característica prestacional dos direitos fundamentais sociais está o problema da efetiva disponibilidade do seu objeto. Ou seja, é fundamental observar se o Estado possui condições de dispor da prestação que lhe é reclamada, pois é certo que existe uma dependência em relação a esta disponibilidade de recursos com o cumprimento do 
objeto da norma em questão.

O STJ, no julgamento do REsp 635.949/SC entendeu que a ideia de reserva do possível assenta-se na premissa de que a obrigação impossível não pode ser exigida, porquanto, a insuficiência de recursos não pode ser considerada mera falácia. Assim, a reserva do possível está intrinsecamente ligada ao problema da escassez, contudo, não pode ser compreendida como sinônimo de desigualdade social.

$\mathrm{Na}$ verdade, a reserva do possível pode ser considerada um conceito econômico, pois conforme discorre Scaff (2012), decorre da constatação da falta de recursos públicos em face da imensa gama de necessidades humanas, sociais, coletivas ou individuais. Realizando uma comparação, se cada indivíduo ao realizar suas escolhas e eleger prioridades deve levar em consideração suas disponibilidades financeiras, o mesmo vale para as escolhas feitas pelo Estado em sede de execução e implementação das políticas públicas.

Embora os Tribunais considerem a não oponibilidade da reserva do possível em detrimento ao cumprimento dos direitos positivos, não deixam de conferir a devida importância, ponderando sobre o assunto, que é bastante complexo. Desse modo, os julgamentos não têm ignorado o fato de que a realização dos direitos sociais depende indubitavelmente de um vínculo financeiro, subordinado as possibilidades orçamentárias Estatais, de modo que se restar comprovada a alegação da incapacidade econômica por parte do Estado, não se poderá exigir a imediata efetivação do preceito elencado no texto Constitucional.

No julgamento do RE 482.611/SC, o Supremo assevera que não se pode deixar de dar a significativa importância ao tema, vez que notadamente, no que diz respeito à implementação e efetivação (em sua totalidade onerosas) dos direitos sociais, o adimplemento pelo Poder Público, sempre impõe e exige prestações estatais positivas de caráter financeiro, para que através delas, sejam efetivadas as prerrogativas individuais e coletivas.

Contudo, essa situação somente será admissível, segundo entendimento expressado no julgamento da ADPF 45, na ocorrência de justo motivo objetivamente aferível. Ou seja, o entendimento supra somente é plausível caso reste comprovada de maneira objetiva à incapacidade financeira Estatal, não se utilizando a referida limitação para criar obstáculo a fim de fraudar as condições materiais mínimas de existência. 
Assim, é fato que a satisfação dos direitos fundamentais encontra como fator limitador a reserva do possível, principalmente no tocante a dependência a capacidade orçamentária do Estado.

\subsection{A Intangibilidade do Princípio do Mínimo Existencial Frente à Cláusula da Reserva do Possível}

Em um primeiro momento, ressalta-se o posicionamento jurisprudencial no sentido de que a reserva do possível não pode ser oposta como justificativa ao não cumprimento do princípio do mínimo existencial, que pode ser compreendido como um núcleo de condições materiais mínimas de sobrevivência. O mínimo existencial deve ser intangível para que sejam asseguradas, ao menos, as condições mínimas para uma vivência digna.

Nesse diapasão, o Supremo Tribunal Federal, ao julgar o RE 639.337/SP, entende que por resultar implicitamente dos preceitos Constitucionais que asseguram como fundamental o princípio da dignidade da pessoa humana e como objetivo fundamental a erradicação da pobreza, marginalização e desigualdades, o princípio do mínimo existencial, não pode, de forma alguma, ser desrespeitado. Isso quer dizer, que mesmo com as reservas financeiras, deve ser observada a sua intangibilidade, de modo que as decisões governamentais tenham sempre como parâmetro e prioridade a dignidade da pessoa humana.

Não obstante, ainda analisando o julgamento acima mencionado, destacouse que a cláusula da reserva do possível encontra limitação na garantia constitucional que é o mínimo existencial, que no contexto do ordenamento jurídico atual, representa emanação direta do princípio essencial da dignidade da pessoa humana.

Isso porque, para a maior parte da jurisprudência e da doutrina, a justificativa quanto aos recursos financeiros escassos não é plausível, já que a ausência da estrutura econômica necessária para implementação das políticas públicas e o consequente não cumprimento dos direitos fundamentais, importa em infringência a Constituição Federal. O “administrador público está vinculado à Constituição [...] para a implementação das políticas públicas relativas à ordem social constitucional, 
ou seja, a sua própria finalidade: o bem estar e a justiça social" (TROTTE, 2012, p. 09). Isto é, quando se infringe o princípio do mínimo existencial, além da dignidade da pessoa humana, está se desrespeitando a Constituição.

Não obstante, existe orçamento através do qual o Poder Público poderá escolher os recursos que serão destinados ao cumprimento desses direitos Constitucionalmente assegurados. Esta é a ocasião oportuna para o legislador estar atento as questões referentes às viabilidades orçamentárias para execução das políticas públicas. Segundo Scaff (2012) é o legislativo que possui o poder quanto à destinação dos gastos, pois foi a ele que a sociedade concedeu esse poder de escolha. Assim, quando da elaboração do orçamento, o Poder Público sempre deverá primar para que sejam asseguradas com prioridade, as garantias mínimas para uma vivencia com dignidade.

Exatamente neste contexto referente à realização das escolhas orçamentárias a fim de assegurar os direitos sociais, que advém a discussão a respeito das escolhas trágicas, pois uma vez que incide sobre o poder público obrigação de tornar efetivas as prestações sociais e que os recursos financeiros são finitos, é necessário escolher em que área será aplicado o dinheiro, priorizando um direito em detrimento de outro. Contudo, o mínimo existencial não pode ser postergado e deve ser prioridade do Poder Público. Somente depois de atendido o mínimo existencial que se pode cogitar a efetivação de outros gastos. Assim, se primeiramente deverão ser alocados recursos financeiros para o cumprimento do mínimo existencial, logicamente que serão chamadas de escolhas trágicas, porque, na prática, são aplicados maiores recursos financeiros a favor de alguns cidadãos em detrimento do direito de outros, quando o ideal seria que houvesse organização orçamentária para efetivação de todos os direitos assegurados pela legislação de regência. Entretanto, considerando-se que esta hipótese é utópica, persiste a questão das escolhas trágicas.

A tese da existência de escolhas trágicas surgiu através da edição da obra escrita por Guido Calabresi e Philip Bobbit, "Tragic Choices - The conflicts society confronts in the allocation of tragically scarce resources" (Escolhas trágicas - Os conflitos que a sociedade encontra na alocação trágica dos recursos escassos), e é caracterizada, em sede de políticas públicas, conforme mencionado anteriormente, pela escolha da execução de um direito em detrimento de outro.

Gastar mais com alguns cidadãos do que com outros deve envolver um 
critério distributivo acerca desses recursos. Esta é a orientação jurisprudencial do STF, de modo que quando o Estado gasta recursos para assegurar os direitos fundamentais sociais de uma forma universal, por outro ângulo, deve garantir também valores variáveis em decorrência das necessidades particulares de cada cidadão. Assim, considerando que não existem recursos suficientes para a satisfação de todas as necessidades sociais, a política pública vinculada para implementação e execução dos direitos sociais implicaria em escolhas específicas e alocativas, ou seja, a quem beneficiar e o quanto dispor para tal.

Analisando outro aspecto importante, é sabido, que embora os recursos financeiros Estatais sejam limitados, consoante ensina Barcellos (2011), a margem de crédito é bastante elástica, haja vista a possibilidade do aumento da receita através do aumento dos tributos, por exemplo. Isso quer dizer que, bastando organização orçamentária, em um espaço relativamente curto, o Estado pode majorar sua capacidade financeira. Ou seja, é menos oneroso argumentar a existência da cláusula da reserva do possível como justificativa ao não cumprimento do princípio do mínimo existencial do que reestruturar e priorizar a questão organizacional quanto à distribuição das verbas e os respectivos custos referentes às políticas públicas para efetivação dos direitos sociais.

Assim, a harmonia entre o mínimo existencial e a reserva do possível aconteceria se fossem priorizados os gastos com o que a Constituição Federal considera como fundamental, a exemplo, os direitos sociais. A Constituição é extremamente objetiva nesse sentido ao dispor como fundamental, entre outros, a dignidade da pessoa humana. Fundamental, nesse caso, significa prioritário.

Por fim, as ações públicas, projetos e investimentos financeiros devem ter como alvo primário, a concretização do princípio da dignidade da pessoa humana mínimo existencial - para que somente depois, sejam definidos em quais aspectos deverão ser destinadas as demais verbas orçamentárias.

\section{DA SUPOSTA VIOLAÇÃO AO PRINCÍPIO CONSTITUCIONAL DA SEPARAÇÃO DOS PODERES E À DEMOCRACIA}

No que tange ao desrespeito ao princípio da separação dos poderes, a discussão advém da afirmação de que a ingerência indevida do Poder Judiciário no critério discricionário do Poder Executivo fere o referido princípio Constitucional. Isso 
porque, justamente a fim de preservar a separação funcional dos poderes, é vedado ao Judiciário, ao menos em tese, julgar as questões referentes ao mérito dos atos administrativos, apreciando apenas a legalidade, posto que atribuir juízo de valoração ao ato através do que for mais conveniente e oportuno é atribuição do Poder Executivo.

Os principais argumentos nesse sentido se fundamentam no fato de que não deve o judiciário adentrar no mérito do ato administrativo, revisando o juízo de oportunidade e conveniência do Poder Executivo, salvo motivo de ilegalidade, defeito formal ou abuso de poder. Nesse sentido, afirma-se que os entes possuem a liberalidade de escolher onde devem ser aplicadas as verbas orçamentárias e o que deve ser prioridade, não cabendo ao Judiciário intervir, sob pena de desrespeitar o princípio da separação dos poderes.

A Constituição Federal, em muitos casos atribui competência privativa ao Poder Legislativo para editar leis sobre a execução dos direitos fundamentais e a falta dessa normatização se torna um obstáculo para a eficácia de tais direitos. "Por um lado, existiria a eficácia direta do direito fundamental. Por outro, a competência do Poder Legislativo para disciplinar concretamente o referido direito fundamental" (JUSTEN FILHO, 2011, p. 162) e por fim, a competência do Poder Executivo para ordenar o modo de aplicação. Assim, se a execução dos direitos fundamentais deve ser imediata e não existe normatização específica a respeito ou o executivo falha em sua execução, obrigando o judiciário a atuar no sentido de assegurar tais direitos, existiria um conflito de princípios (separação dos poderes, intangibilidade dos direitos fundamentais e sua aplicação imediata, discricionariedade e democracia).

Não obstante, conforme aduz Fonte (2009), o tema ganha maior complexidade quando se leva em consideração que as políticas públicas são criadas pela Constituição Federal, sendo originárias de órgãos Estatais eleitos democraticamente e executadas pelo Poder Executivo. Entretanto, o Poder Judiciário não possui membros eleitos democraticamente, de modo que sua interferência na formulação e realização de tais políticas impediria que os demais Poderes levassem a efeito seus projetos da maioria para o Estado, abalando a separação dos Poderes e a democracia.

Entretanto, no que diz respeito ao argumento democrático majoritário consistente em atender a vontade democrática da maioria, Comparato (1998) leciona que a democracia nunca é fruto de uma evolução natural da sociedade 
política. Ao contrário, se institucionaliza através da organização das instituições políticas em defesa dos do princípio da dignidade da pessoa humana e que nesse delicado processo de construção institucional da democracia, aos juristas é atribuída função hegemônica.

$\mathrm{Na}$ verdade, a democracia, para atender a sua perfeita conceituação, juntamente com a aplicação da regra majoritária, deve ser aplicada com o devido respeito aos direitos fundamentais. Os direitos fundamentais são, na verdade, condições para o regime democrático.

\begin{abstract}
A separação dos poderes, em seu modelo clássico, confere a um órgão, o Legislativo, o poder de elaborar as leis. Entretanto, como consequência da igualdade de todos os homens, o poder de decidir sobre o que quer que afete a coletividade só pode pertencer à própria coletividade, isto é, a um conjunto de indivíduos. Ademais, uma vez que a opinião de cada um tem idêntico valor, o único critério de decisão admissível, em tese, é o majoritário. A soberania popular democrática é, portanto, antes de tudo, um corolário do princípio da igualdade. (BARCELLOS, 2011, p. 265).
\end{abstract}

Assim, calcado no princípio da igualdade, onde até mesmo a minorias devem ser respeitadas em sua humanidade, conforme discorre Barcellos (2011), é possível concluir que nem o princípio da separação dos poderes e nem o princípio majoritário são absolutos, não podendo dirimir as garantias fundamentais sob a argumentação da aplicação de um princípio ou de outro de maneira estrita. Ora, se a finalidade de tais princípios é a garantia da dignidade da pessoa humana e dos direitos fundamentais, então, qual o sentido de aplicar os referidos princípios contra o próprio fim a que se destinam?

A verdadeira legitimidade do Judiciário, conforme discorre Lopes Jr. (2004), se origina no critério democrático da Constituição e não da vontade da maioria, eis que o Juiz possui uma nova colocação em relação ao Estado democrático de direito e a sua legitimidade não é política, mas constitucional, fundamentada na intangibilidade dos direitos fundamentais. Esta legitimidade democrática, por sua vez, está calcada na garantia de aplicação efetiva desses direitos.

O que se pode dizer desde logo é que a separação de poderes em si mesma não representa um obstáculo lógico ao controle pelo Poder Judiciário das ações ou omissões inconstitucionais praticadas pelo poder público, aí incluída a determinação de prestações positivas com fundamento constitucional [...].

Como se sabe, entre o exercício monolítico do poder pelo judiciário e a completa vedação do controle judicial de constitucionalidade dos atos comissivos ou omissivos, do poder público- de um extremo a outro- há um 
longo trajeto de possibilidades que podem ser trilhados legitimamente [...], mantendo-se ainda eficiente controle dos poderes por meio da divisão das funções. Isso será especialmente verdadeiro quando o controle de constitucionalidade disser respeito à proteção de direitos fundamentais, fim último, afinal, da própria separação dos poderes. (BARCELLOS, 2011, p. 264).

Ademais, o entendimento de que o controle judicial de políticas públicas fere a Separação dos poderes é entendimento superado pelo STF e a moderna doutrina. O princípio da separação dos poderes, interpretado atualmente de maneira mais abrandada, não pode sofrer restrições baseado apenas em sua especialidade funcional. A separação dos poderes não veda a interferência não habitual de um Poder na função de outro, desde que seja compatível com a sua atividade finalística, que no caso do Poder Judiciário, é de natureza jurisdicional, de aplicação da lei ao caso concreto.

\begin{abstract}
A separação dos Poderes se assenta na especialização das funções do Estado e não veda o exercício, a título ocasional, de uma determinada função por órgão não-especializado, desde que compatível com sua atividade-fim. Já a reserva absoluta da lei implica a destinação específica da regulação de uma dada matéria - inclusive as formas de exercício de um determinado direito - à atividade legislativa, a qual não pode ser exercida pelos membros dos demais Poderes. É da própria natureza do Poder Judiciário interferir sobre o exercício das atividades dos demais Poderes, na medida em que é o Poder constitucionalmente responsável pela função de verificar a compatibilidade destas atividades com a Constituição Federal. (APPIO, 2004, p. 234).
\end{abstract}

Ademais, observando-se que a separação dos poderes não necessita absoluta rigidez para atingir a finalidade de conter o exercício arbitrário do poder e proteger os direitos fundamentais, sua aplicação estrita e absoluta ocasionaria o efeito inverso.

Propõe Justen Filho (2011), que a resposta para esse conflito está no princípio da proporcionalidade. E expõe duas soluções. A primeira consiste em observar a relevância do direito fundamental que não pode ser ignorada pelo administrador, posto que se a aplicação absoluta do princípio da separação dos poderes for considerada, estará certamente dirimindo um direito fundamental de ser efetivado, ao menos, minimamente. Entretanto, importante observar que nem os direitos fundamentais e nem o princípio da separação dos poderes deverão ser aplicados de maneira absoluta e permanente, sendo que as providências tomadas, mesmo na ausência de previsão legal, devem ser fundadas na Constituição Federal 
e indispensáveis a realização do direito fundamental.

A outra solução apresentada pelo autor está baseada na impossibilidade de uma solução unificada para os inúmeros casos em que se torna necessária à ingerência do judiciário na aplicação das políticas públicas. Isso porque, não haveria tempo hábil para a discussão de um problema em específico a ser normatizado pelo legislativo e efetivado pelo Executivo, vez que nesses casos a urgência é fator preponderante e a execução do direito é fundamental para quem necessita da atuação jurisdicional. É nesse contexto que se reconhece o direito ao mínimo existencial, independentemente de qualquer disposição normativa infraconstitucional.

Nesse diapasão, o referido princípio resolve de forma clara a questão, sem que exista desrespeito à separação dos poderes. Corrobora Novelino (2009), que para justificar a constitucionalidade do ato praticado, é necessário observar os requisitos essenciais que o tornaram a solução mais adequada ao caso, que se fundamenta na necessidade de que o meio utilizado para alcançar determinada finalidade seja o menos oneroso possível, sob pena de se tornar medida inconstitucional, bem como a adequação entre o método e o fim adotado para alcançar o objetivo almejado e por fim, a proporcionalidade em sentido estrito, pois a medida adotada necessita ter um bônus maior para o cidadão que o ônus imposto para sua realização.

Assim, tendo em vista a intangibilidade dos direitos fundamentais e que os principais destinatários dos direitos sociais são as classes mais fragilizadas e hipossuficientes e que a implementação dessas prestações é realizada através de políticas públicas destinadas a fomentar os direitos necessários a uma existência (ao menos minimamente) digna e observando-se ainda, proporcionalidade entre a necessidade do meio utilizado e a adequação ao ato exigido, se justifica a judicialização das políticas públicas, como a forma mais célere de sanar o direito essencial que foi lesado, sem que para tanto, exista ofensa ao princípio constitucional da separação dos poderes.

\section{CONSIDERAÇÕES FINAIS}

Após análise das decisões selecionadas para esta pesquisa, bem como o entendimento da doutrina contemporânea, pode-se concluir que a Constituição 
Federal deve ser interpretada a luz do princípio constitucional da dignidade da pessoa humana e a partir desse pressuposto, serão resolvidas as controvérsias pertinentes ao controle judicial das políticas públicas e a implementação dos direitos fundamentais sociais.

Dito isso, observe-se que os direitos sociais são fundamentais para atender esse princípio basilar, não estando condicionados aos critérios de oportunidade e conveniência da Administração Pública. Aqueles direitos que estão intimamente ligados à dignidade da pessoa humana não podem ser limitados em razão da escassez, quando esta é fruto da vontade do administrador.

Ademais, em relação ao princípio da separação dos poderes, fundamenta-se que não há a ingerência indevida do Judiciário em hipóteses excepcionais de omissão ou quando o ato não atingir o fim o qual se destinou. Isso porque, o princípio da separação dos poderes, interpretado atualmente de maneira mais relativizada, não pode sofrer restrições baseado apenas em sua especialidade funcional. A separação dos poderes não veda a interferência não habitual de um Poder na função de outro, desde que seja compatível com a sua atividade finalística, que no caso do Poder Judiciário, é de natureza jurisdicional, de aplicação da lei ao caso concreto. Se o referido princípio for interpretado estritamente, ocorrerá o exercício arbitrário do poder, causando efeito exatamente contrário à função para o qual foi criado.

No que tange a questão financeira necessária para efetivação dos direitos prestacionais, os julgamentos não têm ignorado o fato de que a realização dos direitos sociais depende inescapavelmente de um vinculo financeiro, subordinado as possibilidades orçamentárias Estatais, de modo que se restar comprovada objetivamente a alegação da incapacidade econômica financeira por parte do Estado, não se poderá exigir a imediata efetivação do preceito elencado no texto Constitucional.

O problema reside exatamente na comprovação da insuficiência de recursos pelo Estado. Isso porque, na maior parte dos casos, a cláusula da reserva do possível é utilizada indiscriminadamente, sem comprovação objetiva, como forma de burlar as condições materiais mínimas de sobrevivência.

Outro aspecto importante está relacionado à intangibilidade do princípio do mínimo existencial frente à cláusula da reserva do possível. A Constituição, ao assegurar como fundamental o princípio da dignidade da pessoa humana e como 
objetivo fundamental a erradicação da pobreza, marginalização e desigualdades, confirma que o princípio do mínimo existencial, não pode ser desrespeitado. Ou seja, mesmo com as reservas financeiras, deve ser observada a sua intangibilidade, de modo que as decisões governamentais tenham sempre como parâmetro e prioridade a dignidade da pessoa humana.

Por fim, sobre a polêmica questão da legitimidade do Poder Judiciário no controle das políticas públicas, importante observar primeiramente, que o judiciário não possui competência para efetivar as questões de políticas públicas. Inclusive, consentindo que o Poder Judiciário assumisse essa feição, estaria havendo concentração de poderes, violando de plano a separação funcional das funções Estatais. Este posicionamento é incontroverso.

Entretanto, os Tribunais têm admitido que algumas hipóteses excepcionais legitimadoras o controle judicial das políticas públicas, senão vejamos.

A omissão do Estado que deixa de cumprir preceito constitucional é qualificada, de acordo com o entendimento preponderante do STF como comportamento de extrema gravidade e autoriza a intervenção do Poder Judiciário a fim de restaurar a ordem Constitucional violada.

Ademais, deve sempre prevalecer à primazia da Constituição Federal, não podendo ser reduzida a mera letra de lei, sem efetividade e que em muitos casos, por conveniência e oportunidade na omissão dos poderes públicos é transgredida. Decorrente do desrespeito à primazia da Constituição existe o fenômeno da erosão da Consciência Constitucional, motivado pela desvalorização funcional da Constituição, através da abstenção do Poder Público de cumprir, ainda que parcialmente, preceito Constitucional.

Assim, tanto a primazia da Constituição quanto o receio de que o fenômeno da erosão Constitucional continue se alargando, são hipóteses legitimadoras da interferência do Poder Judiciário no Poder Público, a fim de neutralizar os efeitos dos atos que insultam a Constituição Federal.

Outro argumento que legitima o controle Judicial das políticas públicas se refere ao fato de que a lei não pode prever as reais necessidades do direito material em si, pois assumem contornos diversos dependendo do caso em questão. Diante dessa realidade, naturalmente os Judiciário adequou os instrumentos processuais de modo a sanar a tutela dos direitos fundamentais pretendidos, até então, negados pelo Estado. 
Por fim, no que diz respeito à amplitude da legitimidade que o Poder Judiciário possui na judicialização das políticas públicas, pode ser respondida através de argumentação baseada na ponderação e racionalidade na atividade jurisdicional. Sendo o princípio da dignidade da pessoa humana considerado como primordial, o princípio da separação dos poderes e o princípio majoritário (vontade democrática das maiorias) devem atuar da maneira harmônica com a positivação da dignidade e do mínimo existencial, reconhecendo assim, a legitimidade do Judiciário para determinar as políticas adequadas à satisfação de tais direitos.

Desse modo, indubitavelmente, o principal fator autorizativo da legitimação da interferência do Judiciário na Administração é, o desrespeito à dignidade humana, princípio fundamental do ordenamento jurídico vigente.

Assim, conclui-se a respeito da pesquisa realizada que embora o Poder Judiciário interfira nos critérios de oportunidade e conveniência do Poder Executivo, o entendimento de que não há legitimidade nessa intervenção caiu por terra à quando o Judiciário agindo de forma ponderada, razoável e proporcional, assegura a dignidade da pessoa humana e o núcleo consubstanciador das condições materiais para o mínimo existencial, controlando a aplicação das políticas públicas até então negadas pelo Estado, seja por ato desviado da finalidade que se destinava, ou pela negativa na prestação de cunho social.

Existem muitos fatores contraditórios na judicialização das políticas públicas, inclusive orçamentários (cláusula da reserva do possível). Contudo, é desejável que o Poder Público, quando da elaboração orçamentária, considere como fundamental (porque de fato é) a disponibilização de recursos para a efetivação dos direitos sociais, de modo a assegurar o disposto na Lei Maior.

Sabe-se que os recursos são escassos e limitados, tendo em vista as inúmeras necessidades sociais e exatamente por este fator preponderante que são tomadas decisões consideradas escolhas trágicas. Quando não se podem efetivar todos os direitos com uma eficácia significativa, a preferência é dada aqueles que são fundamentais, elementares. Observe-se que todos os direitos dispostos na legislação vigente são importantes e possuem um alto significado no contexto social que estão inseridos, mas aquele conjunto de condições materiais mínimas de sobrevivência (considerado núcleo essencial ou mínimo existencial) deve ser tido como prioridade.

Nesse tocante, o mínimo existencial deve ser observado como preferência 
de escolha quando da alocação dos recursos financeiros pelo Estado. Quando o Poder Executivo não o faz, está autorizado o Poder Judiciário a intervir e restabelecer a ordem violada e o direito preterido a quem dele necessita. E o motivo resume-se no princípio da dignidade da pessoa humana.

\section{REFERÊNCIAS}

ÁPPIO, Eduardo Fernando. O controle judicial das políticas públicas no Brasil. 2004. 473 f. Tese (Doutorado em Direito) - Programa de doutorado em direito, Universidade Federal de Santa Catarina, Florianópolis, 2004.

BARCELLOS, Ana Paula de. A eficácia jurídica dos princípios constitucionais. $3^{\underline{a}}$ ed. Revista e atualizada. Rio de Janeiro: Renovar, 2011.

BARROSO, Luis Roberto. Direito constitucional contemporâneo. Os conceitos fundamentais e a nova construção do novo modelo. $1^{\underline{a}}$ ed. São Paulo: Saraiva, 2009.

BINENBOJM, Gustavo. A Constitucionalização do Direito Administrativo no Brasil: Um Inventário de Avanços e Retrocessos. Revista eletrônica sobre reforma do Estado. Instituto Brasileiro de direito público, n. 13, Bahia, p. 02-43, n.13, mar./abr./mai. 2008.

BONAVIDES, Paulo. Ciência Política. 10ª ed. Revista e atualizada. São Paulo: Malheiros, 2003.

. Curso de Direito Constitucional. 15를 ed. São Paulo: Malheiros, 2003.

BRASIL. Constituição Federal. Brasília: Senado Federal, 1988. Disponível em: http://www.planalto.gov.br/ccivil 03/constituicao/constituicaocompilado.htm. Acesso em: 15 jan. 2015.

. Supremo Tribunal Federal. Arguição de Descumprimento de Preceito Fundamental. ADPF 45. Partido Social da Democracia Brasileira (PSDB) e Advocacia Geral da União. Relator: Ministro Celso de Mello. 29 de abril de 2004. Disponível em:

http://www.stf.jus.br/portal/peticaolnicial/verPeticaolnicial.asp?base=ADPF\&s1=45\&p rocesso $=45$. Acesso em: 19 março de 2015.

. Supremo Tribunal Federal. Acórdão de decisão que negou pedido de exoneração do encargo constitucional do Estado de prover a educação infantil. Recurso Extraordinário com Agravo no 639.337. Ministério Público do Estado de São Paulo e Município do Estado de São Paulo. Relator: Ministro Celso de Mello. 23 de agosto de 2011. Disponível em:

http://redir.stf.jus.br/paginadorpub/paginador.jsp?docTP=AC\&doclD=627428. Acesso 
em: 02 de dezembro de 2014.

. Supremo Tribunal Federal. Acórdão de decisão que negou provimento ao pedido do Estado do Ceará, de exoneração do encargo de fornecer medicamento de alto custo. Agravo Regimental na Suspensão de Tutela Antecipada no 175. Ministério Público Federal, Estado de Santa Catarina e Município de Florianópolis. Relator: Ministro Gilmar Mendes. 17 de março de 2010. Disponível em: http://redir.stf.jus.br/paginadorpub/paginador.jsp?docTP=AC\&doclD=610255. Acesso em 12 de fevereiro de 2015.

. Superior Tribunal de Justiça. Acórdão de decisão que negou provimento ao pedido do Estado de Mato Grosso do Sul, afim de não fornecer de materiais hospitalares. Recurso Especial nº 1.041.197. Ministério Público de Mato Grosso do Sul e Estado de Mato Grosso do Sul. Relator: Ministro Humberto Martins. 25 de agosto de 2009. Disponível em:

https://ww2.stj.jus.br/processo/revista/documento/mediado/?componente=ATC\&sequ encial $=5649514 \&$ num registro $=200800598307 \&$ data $=20090916 \&$ tipo $=91 \&$ formato $=P$ DF. Acesso em 25 de janeiro de 2015.

BUCCI. Maria Paula Dallari. Políticas Públicas e Direito Administrativo. Revista de informação Legislativa, Brasília, v. 34, n. 133, p. 89-98, jan./mar. 1997.

COMPARATO, Fábio Konder. Ensaio sobre o juízo de constitucionalidade das políticas públicas. Revista de informação legislativa, Brasília, v. 35, n. 138, p. 35138, abr./jun. 1998.

FERREIRA, Ruan Espíndola. Políticas Públicas e Limites ao Poder Discricionário. Analise da STA- AGR 175. Revista de direito da UFU- Universidade Federal de Uberlândia, Uberlândia, v. 41, n. 01, p. 01-29, jan./jun. 2013.

FONTE, Felipe de Melo. A legitimidade do Poder Judiciário para o controle judicial de políticas públicas. Revista eletrônica de direito administrativo, Salvador, n. 18, p. 01-34, maio/jun./jul. 2009.

FREIRE JR., Américo Bedê. O controle judicial de políticas públicas no Brasil. 2004, 117 f., Dissertação (Mestrado em Direito) - Curso de Pós-Graduação em Direitos e Garantias Constitucionais Fundamentais, Faculdades de Vitória, Vitória, 2004.

JUSTEN FILHO, Marçal. Curso de direito administrativo. $7^{\text {a }}$ ed. Revista e atualizada. Belo Horizonte: Fórum, 2011.

LOPES JR, Aury. Introdução crítica ao processo penal. Fundamentos da Instrumentalidade Constitucional. 8aㅡ ed. Rio de Janeiro: 2004.

MAZZA, Alexandre. Manual de direito administrativo. $3^{\underline{a}}$ ed. Atualizada. São Paulo: Saraiva, 2013.

MELLO, Celso Antônio Bandeira de. Curso de direito administrativo. 26ª ed. São Paulo: Malheiros editores, 2008. 
NOVELINO, Marcelo. Direito Constitucional. 5aㅗ ed. São Paulo: Método, 2009.

PAULO, Vicente, ALEXANDRINO, Marcelo. Direito administrativo descomplicado. 5ª ed. São Paulo: Método, 2012.

SARLET, Ingo Wolfgang. A Eficácia dos Direitos Fundamentais. 10. ed. Porto Alegre: Livraria do Advogado, 1998.

SCAFF, Fernando Facury. Reserva do possível pressupõe escolhas trágicas.

São Paulo: 2012, Disponível em: http://www.conjur.com.br/2013-fev-26/contas-vistareserva-possivel-pressupoe-escolhas-tragicas, acesso 2013.

SILVA, José Afonso. Curso de direito constitucional positivo. 9aㅡ ed. São Paulo: Malheiros, 1992.

TROTTE, Natália Bodstein. Teoria das escolhas trágicas e o direito a saúde. Revista da Escola da Magistratura Superior do Rio de Janeiro, Rio de Janeiro, v.15, n.58, p. 02-32, abr./mai./jun. 2012. 